hyperproliferation observed. Hyperproliferation in response to hypoxia in WT cells could be blocked by addition of IL-33. IL-33 stimulation also decreased the phosphorylation of p38 MAP kinase. There was no effect of IL-33 on ST2-/- cells.

Conclusions Mouse pulmonary artery fibroblasts hyperproliferate in response to hypoxia and in the absence of the ST2 receptor. This hyperproliferation involves phosphorylation of p38 MAP kinase. This phosphorylation and excessive cell proliferation can be blocked by ST2/IL-33 signalling. ST2 may be a potentially novel therapeutic target in the PAH.

\section{S156 CHLORIDE INTRACELLULAR CHANNEL PROTEIN 4 (CLIC4) IN THE REGULATION OF HUMAN PULMONARY ENDOTHELIAL RESPONSES TO HYPOXIA}

doi:10.1136/thx.2010.150953.7

V B Abdul-Salam, M R Wilkins, B Wojciak-Stothard. Imperial College London, London, UK

Introduction and Objectives CLIC-4 belongs to the family of chloride intracellular channels, proteins structurally homologous to glutathione transferases. CLIC4 has been implicated in tumour angiogenesis and signalling pathways important in the pathogenesis of pulmonary arterial hypertension (PAH). We have previously demonstrated increased CLIC4 protein expression in whole lung samples from patients with $\mathrm{PAH}$ and animals with chronic hypoxiaand monocrotaline-induced PH. CLIC4 is particularly abundant in pulmonary endothelium of patients with $\mathrm{PAH}$. In this project we aimed to establish a role of CLIC4 plays in the regulation of pulmonary endothelial cell responses to hypoxia.

\section{HYPOXIA}

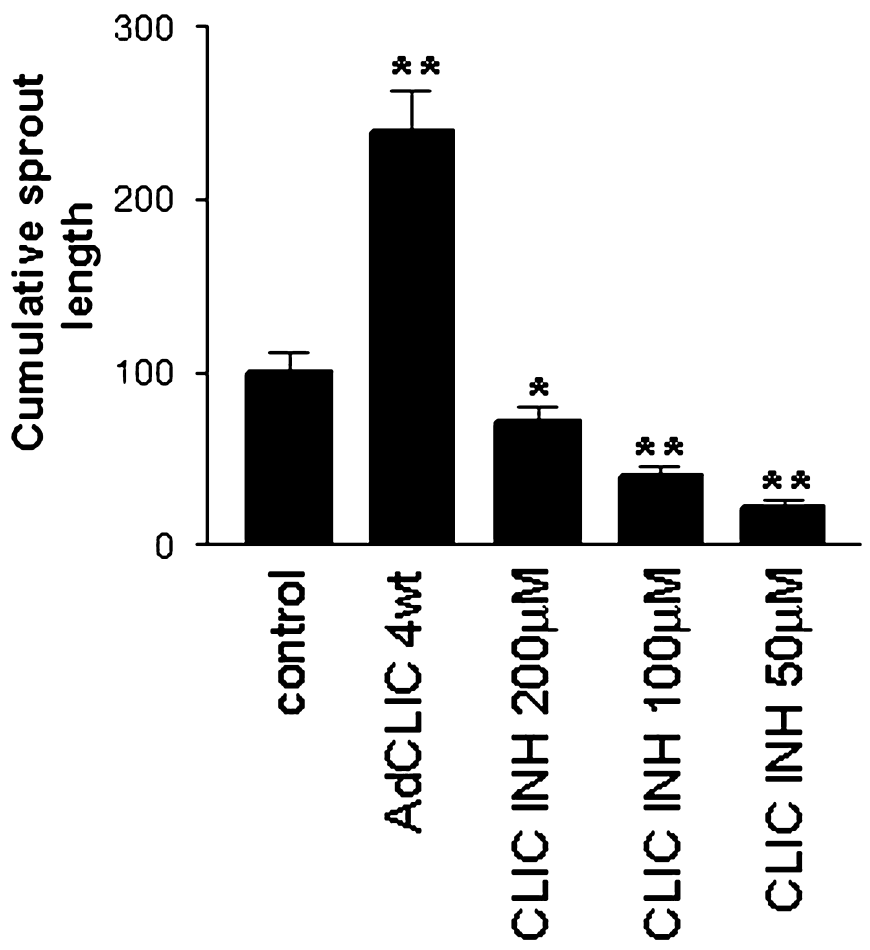

Abstract S156 Figure 1 Endothelial spheroids were left untreated, were infected with adenoviruses to overexpress wtCLIC4, or were treated with NPPB, as indicated. The spheroids were then left in normoxia (not shown) or placed in hypoxia $\left(2 \% \mathrm{O}_{2}, 5 \% \mathrm{CO}_{2}, 93 \% \mathrm{~N}_{2}\right)$ for $24 \mathrm{~h}$. The cumulative sprout length was studied with image analysis software (Image J). ${ }^{*} \mathrm{P}<0.05 ;{ }^{* *} \mathrm{P}<0.01 ; \mathrm{n}=4$.
Methods Human pulmonary artery endothelial cells (HPAECs) were cultured in normoxic conditions or were exposed to hypoxia $\left(2 \% \mathrm{O}_{2}\right.$, $5 \% \mathrm{CO}_{2}, 93 \% \mathrm{~N}_{2}$ ) for 1-24 h. CLIC4 expression and localisation was studied by Western blotting, immunofluorescence and confocal microscopy. The wildtype and nuclear-targetted CLIC4 were overexpressed via adenoviral gene transfer while chloride channel inhibitor NPPB (5-Nitro-2-(3-phenylpropylamino)benzoic acid) was used to inhibit CLIC4 activity. We studied the effects of CLIC4 on endothelial permeability, angiogenesis and proliferation.

Results Overexpression of the wildtype CLIC4 in HPAECs increased pulmonary endothelial proliferation, compromised barrier function and increased angiogenic responses to chronic hypoxia in vitro (Abstract S156 Figure 1). These effects were prevented by chloride channel inhibitor NPPB. In normoxic HPAECs CLIC4 was localised predominantly to the cell nucleus and cytoplasm. Upon stimulation with hypoxia, CLIC-4 translocated to the cell periphery, localising in particular to membrane protrusions (filopodia and lamellipodia), the effect mimicked by overexpression of CLIC4.

Conclusions Hypoxia induces translocation of CLIC-4 to the membrane of HPAECs. This behaviour has been linked to increased motility and malignant phenotype in other cell types. CLIC-4 overexpression in HPAECs also increases endothelial cell responses to hypoxia in vitro. These findings suggest increased CLIC-4 expression in PAECs in PAH may play a role in pathogenesis of PAH and provide novel insights in to disease pathogenesis and treatment strategies.

\section{Occupational asthma}

\section{S157 PREVALENCE OF ASTHMA RELATED TO EMPLOYMENT IN THE UK}

doi:10.1136/thx.2010.150953.8

J Szram, S J Schofield, S J MacNeill, P Cullinan. Department of Occupational and Environmental Medicine, Imperial College, London, UK

It is widely held that $10-15 \%$ of adult asthma is causally related to occupation. It is likely that this fraction varies importantly depending on historical and international variations in employment. Further uncertainties arise from misclassification in the diagnosis of asthma and in exposure assessment, particularly if based on selfreport. We carried out a postal survey of adults listed as asthmatic through general practices across the UK. Cases, who were defined as those who had experienced onset of asthma or worsening of preexisting childhood asthma within 2 years of starting a new job, were compared to controls who declared an equivalent onset or deterioration more than 2 years from the start of a job. Of 8535 individuals targeted, $3115(37 \%)$ returned a completed questionnaire. Almost $40 \%$ of these $(n=1198)$ experienced a deterioration of pre-existing childhood asthma or onset of adult asthma whilst working; 441 were cases and 757 controls. A priori analysis of risk was performed using an asthma-specific JEM, the ECRHS asthma 'high risk occupations' and data from the UK SWORD surveillance scheme. Odds ratios (adjusted for sex, smoking and era of onset and stratified by onset type)-displayed in Abstract S157 Table 1-did not suggest an increased risk of asthma within 2 years of starting a high-risk job. A posteriori analysis of all occupations demonstrated an increased risk of asthma within 2 years of starting a new job in sales and elementary occupations. The calculated population attributable risk (PAR) for these occupations was 15.9\% and was higher in women than men. The results from this study suggest that a priori assessment of risk does not identify occupation as a significant cause of asthma in this contemporary adult workforce in the UK. Jobs which do appear to increase risk of new asthma are not those typically associated with an excess risk of the disease. These findings highlight the disparity between epidemiological and clinical assessments of asthma related to occupation, and the need to consider novel occupations as a cause of asthma. 
Abstract S157 Table 1 Summary of results using a priori risk estimates

\begin{tabular}{|c|c|c|c|c|c|}
\hline $\begin{array}{l}\text { Exposure } \\
\text { definition }\end{array}$ & $\begin{array}{l}\text { No of cases } \\
\text { in high-risk } \\
\text { job }\end{array}$ & $\begin{array}{l}\text { No of controls } \\
\text { in high-risk } \\
\text { job }\end{array}$ & $\begin{array}{l}\text { Odds Ratio } \\
\text { adjusted }\end{array}$ & $\begin{array}{l}95 \% \\
\text { Confidence } \\
\text { Interval }\end{array}$ & p value \\
\hline \multicolumn{6}{|l|}{ JEM } \\
\hline All & 81 & 172 & 0.76 & $0.55-1.04$ & 0.08 \\
\hline Adult onset & 59 & 145 & 0.82 & $0.57-1.18$ & 0.29 \\
\hline Childhood worsening & 22 & 27 & 0.62 & $0.31-1.22$ & 0.17 \\
\hline \multicolumn{6}{|l|}{ ECRHS } \\
\hline All & 109 & 215 & 0.90 & $0.68-1.19$ & 0.46 \\
\hline Adult onset & 80 & 181 & 0.98 & $0.71-1.35$ & 0.90 \\
\hline Childhood worsening & 29 & 34 & 0.70 & $0.38-1.29$ & 0.25 \\
\hline \multicolumn{6}{|l|}{ SWORD } \\
\hline All & 9 & 31 & 0.49 & $0.23-1.04$ & 0.06 \\
\hline Adult onset & 6 & 28 & 0.44 & $0.18-1.08$ & 0.07 \\
\hline Childhood worsening & 3 & 3 & 0.85 & $0.16-4.41$ & 0.84 \\
\hline
\end{tabular}

\section{S158 OCCUPATIONAL ASTHMA; REFERRAL PATTERNS FROM PRIMARY CARE IN THE UK}

doi:10.1136/thx.2010.150953.9

${ }^{1} \mathrm{~J}$ L Hoyle, ${ }^{2} \mathrm{~L}$ Hussey, ${ }^{2} \mathrm{R}$ Agius. ${ }^{1}$ North Manchester General Hospital, Manchester, England, UK; ${ }^{2}$ Centre for Occupational \& Environmental Health, The University of Manchester, Manchester, England, UK

Introduction and Objectives Occupational asthma is the commonest reported occupational lung disease in the $\mathrm{UK}^{1}$.The British Occupational Health Research Foundation (BOHRF) ${ }^{2}$ guidelines 2010 recommend that 'all family practices be able to screen for occupational asthma, and have a plan for further management'. The standards of care for occupational asthma ${ }^{3}$ recommend 'early referrals to a specialist with an interest in occupational asthma if such a diagnosis is suspected'. This referral should take place 'after occupational asthma is screened for before important life decisions are made'. (SIGN guidelines ${ }^{4}$ ). Very little is known about the proportion of cases that are referred on to clinical specialists once identified.

Methods The Health \& Occupation Reporting network in General Practice (THOR-GP) at the University of Manchester, collects workrelated ill-health data between 250 and 300 GPs trained to diploma level in occupational medicine. Cases with a diagnosis of occupational asthma reported in 2006-2009 were divided into subgroups by their causative agent. Cases referred to a hospital specialist were compared to those not referred.

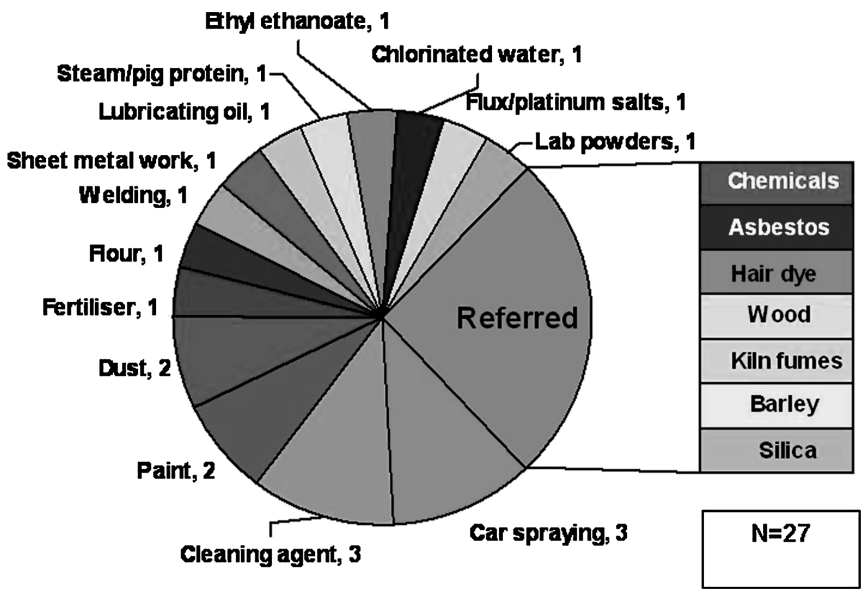

Abstract S158 Figure 1 Agents attributed to asthma cases referred to hospital specialists THOR-GP 2006-2009.
Results In 2006-2009, GPs reported 4902 cases of work-related illhealth, of which $115(2 \%)$ were reports of respiratory disease. 33 were diagnosed with asthma, 6 were referred to a hospital specialist (Abstract S158 Figure 1). The cases not referred included workers exposed to a variety of known asthmagens.

Conclusion Despite national recommendations, these data show that the majority of cases suspected as having occupational asthma are not referred to hospital specialists from primary care. It is not known if the lack of referral affects outcome with regards to disease prognosis, disability or employment status.

\section{S159 DO OCCUPATIONAL ASTHMATICS WITH SMALL CHANGES IN PEF AT WORK HAVE LESS FEV1 DECLINE THAN THOSE WITH LARGER CHANGES?}

doi:10.1136/thx.2010.150953.10

W Anees, V C Moore, P S Burge. Birmingham Heartlands Hospital, Birmingham, UK

Background The significance of consistent small changes in PEF related to work, or records with diurnal variation within the normal range, are disputed. We related PEF changes at diagnosis to longitudinal changes in FEV1 in workers remaining exposed to their causative agent.

Methods 163 consecutive workers attending a tertiary referral clinic were identified. All had a clinical history suggestive of occupational asthma and a diagnostic serial PEF record (Oasys score $>2.50$ ). Average annual rate of $\mathrm{FEV}_{1}$ decline was calculated using simple linear regression for each worker with at least 12 months of FEV1 measurements. PEF responses to work exposure were made from the initial diagnostic PEF record. Subjects were split into tertiles according to their PEF responses. Mean work-rest PEF was $>35 \mathrm{l} / \mathrm{min}$ in the highest tertile and $<20 \mathrm{l} / \mathrm{min}$ in the lowest. Corresponding values for diurnal variation (DV) $\%$ predicted were $\geq 16 \%$ (high) and $<10 \%$ (low) Results Ninety workers had FEV1 measurements for at least 12 months during exposure to the original causative agent (median 2.9 years, IOR $1.8-4.8$ years). The mean annual loss of FEV1 was increased at 101 (SEM 17.7) $\mathrm{ml} /$ year, unrelated to agent; high MW (10), isocyanates (16), metals (13), colophony (9), biocides (10), metal working fluid (7) and others (23). There were no significant differences related to continued smoking or treatment. There were large between individual differences with annual declines $<50 \mathrm{ml}$ in $35 / 90$ workers. There were no statistically significant differences between those with high rest-work PEF changes (-126 SEM $44 \mathrm{ml} /$ year), and low changes (95 SEM $22.1 \mathrm{ml} /$ year), or between those with high DV (98 SEM $36.5 \mathrm{ml} /$ year) and low DV (142 SEM $30.3 \mathrm{ml} /$ year).

Conclusion Some workers with occupational asthma have normal FEV1 decline during continued exposure, but the average is around $3 \times$ predicted. Workers with small work-related PEF changes or low DV do as badly as those with larger values. The classification of FEV1 decline in an individual worker requires longer measurements than we have available; the group mean changes should be more reliable. Those who are able to remain exposed are likely to be those with least severe disease.

\section{S160 THE EFFECT OF SHIFT WORK ON SERIAL PEAK EXPIRATORY FLOW MEASUREMENTS USED TO DIAGNOSE OCCUPATIONAL ASTHMA}

doi:10.1136/thx.2010.150953.11

${ }^{1} \mathrm{~V}$ C Moore, ${ }^{2} \mathrm{M}$ S Jaakkola, ${ }^{1} \mathrm{C}$ B S G Burge, ${ }^{3} \mathrm{C}$ F A Pantin, ${ }^{1}$ A S Robertson, ${ }^{1} \mathrm{P}$ S Burge. ${ }^{1}$ Birmingham Heartlands Hospital, Birmingham, UK; ${ }^{2}$ Oulu University, Oulu, Finland; ${ }^{3}$ University Hospital of North Staffordshire, Stoke on Trent, UK

We investigated the effects of shift work on Peak Expiratory Flow (PEF) measurements used for diagnosing occupational asthma (OA). 